\title{
Perinatal mortality in a first generation immigrant population and its relation to unemployment in The Netherlands
}

\author{
L H Lumey, S A Reijneveld
}

\begin{abstract}
Study objective - To consider the association between biological and social risk factors and perinatal mortality in an ethnically mixed population in Amsterdam, The Netherlands.

Design - This was a matched case-control study. Cases included all registered stillborn infants and all registered liveborn infants who died within seven days of birth. Controls were selected from infants remaining alive. Each case was matched with two controls by date of registration. Setting - Civil registry of births and deaths, Amsterdam, The Netherlands, 1975-80.

Patients - All 666 babies who died in the perinatal period and 1332 controls selected from the liveborn survivors.

Outcome - Perinatal mortality.

Main Results - Perinatal mortality was independently associated with the father's and mother's employment status, maternal age, parity, and infant sex, but not with the father's or mother's country of birth.

Conclusions - Employment status and not country of birth should be the main focus in studies of perinatal mortality in this population of mixed ethnicity. Future studies on selected behavioural, socioeconomic, and cultural factors are needed to provide a better understanding of the causes of increased perinatal mortality among families in which the parents are unemployed.
\end{abstract}

(f Epidemiol Community Health 1995;49:454-459)

Departments of Obstetrics, Gynaecology, and Neonatalogy and of Clinical

Epidemiology and Biostatistics,

Academic Medical Centre, Amsterdam The Netherlands L H Lumey

Department of Epidemiology Municipal Health Service, Amsterdam, The Netherlands S A Reijneveld

Correspondence to: Dr L H Lumey, American Health Foundation, 320 Eas 43rd Street, New York NY 10017, USA

Accepted for publication May 1995 tural factor or to a combination of these. If increased mortality were indeed related to behavioural and cultural risk factors, the public health implications could be considerable, as some of these might be amenable to intervention and could be improved over time.

Between 1975 and 1980 increased perinatal mortality was seen in Amsterdam among firstborn, the unemployed, and among infants of Surinam (odds ratio (OR): 1.50) and other non-Dutch origin (OR: 1.42) compared with infants of Dutch origin in a study carried out by Doornbos and Nordbeck in $1985 .^{1}$ Large scale immigration to The Netherlands from Morocco and Turkey started in the 1960 s when single men arrived for temporary employment and in the 1970s when Surinam families settled in The Netherlands in order to retain Dutch citizenship at Surinam independence in 1975. Because origin was defined by the mother's and father's country of birth, non-Dutch origin nearly always implies first generation immigration as most parents were born in Morocco, Turkey, Surinam, or The Netherlands Antilles. There were no second-generation immigrants from these countries in Amsterdam at the time of the study. Country of birth approximates race and ethnicity for Turkey and Morocco. In Surinam and The Netherlands Antilles, however, the population is of mixed Indian, African, American, and European origin.

Since a more detailed analysis is required for a proper assessment of the role of biological, socioeconomic, and cultural factors in perinatal mortality, a re-analysis of the civil registration data was carried out, matching each case with two controls, and with adequate control of additional variables including paternal and maternal country of birth, paternal and maternal occupational level, and infant sex. At the moment, more recent registration data are not available for analysis.

Subjects and methods

STUDY POPULATION

Cases

Cases included all stillborn infants with a gestational age $\geqslant 28$ weeks and all liveborn infants who died in the first week of life registered at the central Amsterdam civil registration office between 1975 and 1980. Births and deaths in the Amsterdam municipality (population about 700000 ) are recorded in this registry. Registration is considered to be nearly complete for families residing in Amsterdam.

\section{Controls}

The first surviving infants registered before and after each case were selected as controls from the registry records. The difference between date of birth of cases and matched controls was a week or less for $87 \%$ of controls. Only singletons (comprising more than $97 \%$ of cases and controls) were selected for the present 
analysis as we had no specific interest in mortality among multiple births.

VARIABLE SELECTION AND DEFINITION

For cases and controls the registry collected data on maternal age and parity (first births being parity zero, second births parity one, and so on), country of birth and occupation of the parents, marital status, and infant sex. For the cases the date of death was also collected.

The registry recorded the country of birth of each parent in three categories: The Netherlands, Surinam or The Netherlands Antilles, and other non-Dutch. The latter group consists mostly of Turkish and Moroccan born parents as these are presently by far the most important immigrant population groups in The Netherlands.

We defined familial origin by combining paternal and maternal country of birth: families with both parents born in The Netherlands were classified as from Netherlands origin, families with one or both parents born in Surinam or The Netherlands Antilles as from Surinam/The Netherlands Antilles origin, and families with one or both parents born elsewhere as from "other foreign" origin.

Occupation of both parents was classified in five categories based on the 25-level occupational class listing used by the registry. The first category (levels 1-3) includes the self employed and professionals, the second (levels 4-5) and third (levels 6-13) administrative and managerial employees, and the fourth (levels 14-22) the least skilled employees. In the fifth category (levels $23-25$ ) the unemployed, military conscripts, housewives and students are combined to form the "unemployed" group. Household occupational level was defined as the highest of either parent's occupational level. Here the "unemployed" category was assigned to families in which both parents were unemployed, and to single parent families with an unemployed parent. The category "unmarried" in the variables paternal occupational level and paternal country of birth reflects illegitimate births. There are no details on father's occupational situation for infants born to unmarried mothers.
STATISTICAL ANALYSIS

The distribution of selected risk factors for perinatal mortality in relation to maternal country of birth was first analysed in the controls. Differences were evaluated with the $\chi^{2}$ statistic. Next the association of perinatal mortality with maternal country of birth and paternal level of occupation was evaluated. To take the matched study design into account this was carried out with conditional logistic regression models, first separately for each factor and then for both factors combined. We used the EGRET statistical software package ${ }^{2}$ for these analyses.

Finally, the association of perinatal mortality with country of birth and other risk factors was evaluated, separately for each risk factor and again after simultaneous adjustment for other risk factors in conditional logistic regression models. All regression models were conditioned on 666 sets, each comprising one case and two controls. Subjects were missing values on one or more variables were retained in all analyses by creating a separate dummy variable for the missing value category. Variable selection in the regression models was done based on likelihood ratio tests with backward selection procedures.

\section{Results}

The study comprised 1998 infants, of whom 666 died in the perinatal period and 1332 were controls.

PERINATAL MORTALITY RISK FACTORS BY MATERNAL COUNTRY OF BIRTH

Among controls, the maternal country of birth was strongly associated with several well established biological and social risk factors of perinatal mortality such as maternal age, parity, and paternal level of occupation. The differences by maternal country of birth are all statistically highly significant $(p<<0.005)$. Maternal age (less or equal than 19 years or 35 years or over), parity (four or higher), and lower paternal occupational level were more common in families of non-Dutch origin. Most $(55 \%)$ Surinam born women were unmarried (table 1).

Table 1 Risk factors for perinatal mortality in relation to maternal country of birth: civil registry data, Amsterdam, 1975-80. Controls only $(n=1332)$

\begin{tabular}{|c|c|c|c|c|c|c|}
\hline & \multicolumn{6}{|c|}{ Maternal country of birth } \\
\hline & \multicolumn{2}{|c|}{$\begin{array}{l}\text { Netherlands }(n=912) \\
\text { No }\end{array}$} & \multicolumn{2}{|c|}{$\begin{array}{l}\text { Surinam/Antilles }(n=101) \\
\text { No }(\%)\end{array}$} & \multicolumn{2}{|c|}{ Other $(n=138)$} \\
\hline \multicolumn{7}{|l|}{ Maternal age $(y)$; } \\
\hline$\leqslant 19$ & 31 & (3) & 13 & (13) & 26 & $(8)$ \\
\hline $20-34$ & 825 & (91) & 78 & (77) & 259 & (81) \\
\hline$\geqslant 35$ & 32 & (3) & 6 & (6) & 25 & (8) \\
\hline \multicolumn{7}{|l|}{ Parity: } \\
\hline 0 & 513 & (56) & 53 & $(52)$ & 147 & (46) \\
\hline 1-3 & 397 & (44) & 45 & (45) & 139 & (44) \\
\hline$\geqslant 4$ & 2 & $(0 \cdot 2)$ & 3 & (3) & 32 & (10) \\
\hline \multicolumn{7}{|l|}{ Paternal level of occupation: } \\
\hline I-III & 464 & (51) & 19 & (19) & 87 & (27) \\
\hline IV & 280 & (31) & 17 & (17) & 133 & (42) \\
\hline No job & 72 & $(8)$ & 10 & (10) & 68 & (21) \\
\hline Mother not married & 96 & (11) & 55 & (55) & 30 & (9) \\
\hline
\end{tabular}

Maternal age missing for 37 subjects and maternal country of birth for one subject.

Percentages may not sum to 100 due to missing values and/or rounding. 
Table 2 Crude and adjusted* odds ratios (OR) (95\% confidence intervals (CI)) of perinatal mortality for maternal country of birth and paternal level of occupation. Matched conditional logistic regression models. Civil registry data, Amsterdam 1975-80.

\begin{tabular}{|c|c|c|c|c|}
\hline & Crude OR & $(95 \% C I)$ & $\begin{array}{l}\text { Adjusted } \\
\text { OR* }\end{array}$ & $(95 \% C I)$ \\
\hline \multicolumn{5}{|l|}{ Maternal country of birth: } \\
\hline Netherlands & $1+$ & & & \\
\hline Surinam/Antilles & $1 \cdot 28$ & $(0.90,1.80)$ & $1 \cdot 16$ & $(0.81,1.68)$ \\
\hline Other & $1 \cdot 19$ & $(0.95,1.49)$ & $1 \cdot 12$ & $(0.89,1 \cdot 40)$ \\
\hline \multicolumn{5}{|l|}{ Paternal level of occupation: } \\
\hline I-III & 1 & (1) & 1 & (1) \\
\hline IV & $1 \cdot 30$ & $(1.04,1.62)$ & $1 \cdot 28$ & $(1 \cdot 02,1 \cdot 60)$ \\
\hline No job & 1.59 & $(1 \cdot 17,2 \cdot 16)$ & 1.54 & $(1 \cdot 13,2 \cdot 11)$ \\
\hline Mother not married & 1.42 & $(1.07,1.90)$ & 1.37 & $(1.01,1.86)$ \\
\hline
\end{tabular}

* Adjusted for both variables. $\mathrm{O} O \mathrm{R}$ are unity for reference category.

PERINATAL MORTALITY IN RELATION TO SELECTED RISK FACTORS

One or two risk factors

Combining cases and controls, the paternal level of occupation (not adjusted for maternal country of birth) was clearly associated with perinatal mortality. Compared with levels I-III, the odds ratio (OR) for occupational level IV was 1.30 ( $95 \%$ confidence interval (CI): $1 \cdot 04$, 1.62) and for unemployed fathers it was 1.59 (CI: $1 \cdot 17,2 \cdot 16)$. For unmarried fathers (that is, unmarried mothers) it was 1.42 (CI: 1.07 , 1.90). Adjustment for maternal country of birth did not materially affect these estimates (table 2). Maternal country of birth, not adjusted for paternal occupation, was only marginally associated with perinatal mortality. Compared with Netherlands born mothers the OR was 1.28 (CI: $0.90,1.80$ ) for mothers born in Surinam and $1 \cdot 19$ (CI: $0 \cdot 95,1 \cdot 49)$ for mothers born in other foreign countries. Adjustment for paternal level of occupation brings these estimates closer to unity (table 2).

A comparison of the distribution of additional risk factors among cases and controls (table 3, columns 1 and 2) and a matched analysis for each risk factor separately (table 3, column 3) confirms the association of perinatal mortality in the study subjects with other documented risk factors such as maternal age, parity, infant sex, and with paternal country of birth. The risk was significantly lower among mothers without a job compared with mothers with a job (crude OR 0.65, CI: $0.51,0.89$ ) (table 3).

\section{Multiple risk factors}

Simultaneous adjustment for all of the risk factors listed in table 3 was carried out with conditional logistic regression analyses. All variables except paternal and maternal country of birth, or familial origin as the combined measure thereof, contributed significantly to the fully adjusted model $(\mathrm{p}<0.01$, likelihood ratio tests). We therefore list in table 3 (columns 4 and 5) our regression estimates of two final models that do not include country of birth variables. The first model comprises maternal age, parity, infant sex, and paternal and maternal level of occupation and the second model comprises maternal age, parity, infant sex, and the highest level of occupation in the household.

Adjustment for the other variables did not materially change the ORs for any of these except for parities 4 or over compared with

Table 3 Crude and adjusted* odds ratios (OR) (95\% confidence intervals (CI)) of perinatal mortality for selected risk factors. Matched conditional logistic regression models. Civil registry data, Amsterdam, 1975-80.

\begin{tabular}{|c|c|c|c|c|c|c|c|}
\hline & \multicolumn{2}{|c|}{ Cases $(n=666)$} & \multicolumn{2}{|c|}{ Controls $(n=1332)$} & \multirow[t]{2}{*}{ Crude OR ( $95 \%$ CI) } & \multirow{2}{*}{$\begin{array}{l}\text { Adjusted OR* }(95 \% \\
\text { CI) Model \# } 1\end{array}$} & \multirow{2}{*}{$\begin{array}{l}\text { Adjusted OR* } \\
\text { CI) Model \# } 2\end{array}$} \\
\hline & No & $(\%)$ & No & $(\%)^{*}$ & & & \\
\hline \multicolumn{8}{|l|}{ Maternal age $(y):$} \\
\hline$\leqslant 19$ & 47 & (7) & 71 & (5) & $1.37(0.93,2.02)$ & $1 \cdot 20(0 \cdot 80,1 \cdot 80)$ & $1 \cdot 15(0.77,1 \cdot 72)$ \\
\hline $\begin{aligned} & 20-34 \\
\geqslant & 35\end{aligned}$ & 563 & $(85)$ & 1162 & (87) & & & 1 \\
\hline \multirow{2}{*}{\multicolumn{7}{|c|}{ Parity: }} & $1.89(1 \cdot 23,2 \cdot 89)$ \\
\hline 0 & 394 & (59) & 714 & (54) & $1.33(1.09,1.62)$ & & $1 \cdot 41(1 \cdot 14,1 \cdot 73)$ \\
\hline $1-3$ & 242 & (36) & 581 & (44) & & & \\
\hline$\geqslant 4$ & 30 & (5) & 37 & (3) & $1 \cdot 96(1 \cdot 18,3 \cdot 25)$ & $1.46(0.83,2 \cdot 56)$ & $1.48(0.85,2.57)$ \\
\hline \multicolumn{8}{|l|}{ Infant sex: } \\
\hline $\begin{array}{l}\text { Male } \\
\text { Female }\end{array}$ & 388 & $(58)$ & 668 & $(50)$ & $1 \cdot 40(1 \cdot 16,1 \cdot 70)$ & $1.40(1 \cdot 15,1 \cdot 70)$ & $1 \cdot 41(1 \cdot 17,1 \cdot 72)$ \\
\hline \multirow{2}{*}{\multicolumn{7}{|c|}{ Paternal level of occupation: }} & 1 \\
\hline $\begin{array}{l}\text { Paternal level or occupation: } \\
\text { I-III }\end{array}$ & & & & & & & - \\
\hline IV & 230 & (35) & 431 & (32) & $1.30(1.04,1.62)$ & $1.33(1.05,1.68)$ & - \\
\hline Unemployed & 96 & (14) & 150 & (11) & $1.59(1 \cdot 17,2 \cdot 16)$ & $1.72(1.25,2.37)$ & - \\
\hline Mother not married & 105 & (16) & 181 & (14) & $1.42(1.07,1.90)$ & $1.50(1 \cdot 10,2 \cdot 06)$ & - \\
\hline \multicolumn{8}{|l|}{ Maternal level of occupation: } \\
\hline I-III & 143 & $(22)$ & 209 & (16) & 1 & $1.25(0.73,2.15)$ & - \\
\hline $\begin{array}{l}\text { IV } \\
\text { Unemployed }\end{array}$ & $\begin{array}{r}34 \\
489\end{array}$ & $\begin{array}{r}(5) \\
(73)\end{array}$ & $\begin{array}{r}38 \\
1085\end{array}$ & (3) & $\begin{array}{l}1.35(0.80,2 \cdot 27) \\
0.65(0.51,0.83)\end{array}$ & $\begin{array}{l}1.25(0.73,2.15) \\
0.63(0.49,0.82)\end{array}$ & $\begin{array}{l}- \\
-\end{array}$ \\
\hline \multicolumn{5}{|l|}{ Highest household level of occupation: } & & & \\
\hline I-III & 305 & (46) & 663 & (50) & 1 & - & 1 \\
\hline IV & 203 & (31) & 409 & (31) & $1.08(0.87,1.34)$ & - & $1.09(0.87,1.37)$ \\
\hline Unemployed & 158 & (24) & 260 & (20) & $1 \cdot 34(1 \cdot 05,1 \cdot 72)$ & - & $1.44(1 \cdot 12,1 \cdot 87)$ \\
\hline \multicolumn{8}{|l|}{ Paternal birth country: } \\
\hline $\begin{array}{l}\text { Netherlands } \\
\text { Surinam/Antilles }\end{array}$ & $\begin{array}{r}374 \\
20\end{array}$ & $\begin{array}{r}(56) \\
(4)\end{array}$ & $\begin{array}{r}817 \\
47\end{array}$ & $\begin{array}{r}(61) \\
(4)\end{array}$ & & $1.17(0.71,1.93) \ddagger$ & $1.21(0.75,1.98)$ \\
\hline $\begin{array}{l}\text { Surinam/Antilles } \\
\text { Otherf }\end{array}$ & $\begin{array}{r}29 \\
154\end{array}$ & $\begin{array}{r}(4) \\
(23)\end{array}$ & $\begin{array}{r}47 \\
287\end{array}$ & $\begin{array}{l}(4) \\
(22)\end{array}$ & $\begin{array}{l}1.34(0.83,2 \cdot 16) \\
1.18(0.93,1.50)\end{array}$ & $1.03(0.79,1.35) \ddagger$ & $1.05(0.81,1.35) \oint$ \\
\hline \multicolumn{8}{|l|}{ Maternal birth country: } \\
\hline Netherlands & 425 & $(64)$ & 912 & $(69)$ & 1 1 & $1105(072,154)+$ & $110.70,100$ \\
\hline Surinam/Antilles & 60 & (9) & 101 & (8) & $1.28(0.90,1.80)$ & $1.05(0.72,1.54) \ddagger$ & $1.12(0.78,1.62)$ \\
\hline Other & 176 & (26) & 318 & (24) & $1.19(0.95,1.49)$ & $1 \cdot 10(0 \cdot 86,1 \cdot 40) \ddagger$ & $1 \cdot 10(0 \cdot 86,1 \cdot 40) \Phi$ \\
\hline \multicolumn{8}{|l|}{ Familial origin: } \\
\hline Netherlands & 400 & $(60)$ & 837 & (63) & $1.21(0.87 \quad 1.68)$ & & $1.07(0.76,1.52) 8$ \\
\hline $\begin{array}{l}\text { Surinam/Antilles } \\
\text { Other }\end{array}$ & $\begin{array}{r}66 \\
200\end{array}$ & $\begin{array}{l}(10) \\
(30)\end{array}$ & $\begin{array}{l}115 \\
380\end{array}$ & $\begin{array}{l}(19) \\
(29)\end{array}$ & $\begin{array}{l}1 \cdot 21(0 \cdot 87,1 \cdot 68) \\
1 \cdot 11(0.89,1 \cdot 37)\end{array}$ & $\begin{array}{l}0.99(0.69,1.43) \ddagger \\
1.03(0.81,1.30) \ddagger\end{array}$ & $1.03(0.82,1.29) \oint$ \\
\hline Uuct & & (30) & & & $1 \cdot 11(0 \cdot 89,1 \cdot 37)$ & & \\
\hline
\end{tabular}

* For maternal age, parity, infant sex, and either paternal and maternal level of occupation (model \# 1) or highest level of occupation in the household (model For maternal age, parity, infant sex, and either paternal and maternal level of occupation (moriable added to model \# 1 ; $\$ Adjusted ORs for a single country of birth variable added to model \# 2; Percentages may not sum to 100 due to missing values and/or rounding; ORs are unity for reference category. 
parity 1-3. Here adjustment lowered the OR from 1.96 to 1.46 (CI: $0.83,2.56$ ) in the first model and to 1.48 (CI: $0.85,2.57$ ) in the second model. Compared with fathers with a job in level I-III, unemployed fathers were still more likely to have an infant that died $(\mathrm{OR}=$ $1 \cdot 72$, CI: $1.25,2 \cdot 37$ ) in the first model. The risk also remained higher among fathers with a lower level job $(\mathrm{OR}=1.33$, CI: 1.05, 1.68). Maternal unemployment remained associated with decreased mortality in offspring $(\mathrm{OR}=$ 0.63 , CI: $0.49,0.82$ ) (table 3, column 4).

Strata of special importance in the first model include maternal age 35 years or over compared with 20-34 years (OR=1.94 CI: $1.26,3.00)$, nulliparity compared with parity $1-3(\mathrm{OR}=$ 1.28 , CI: $1.03,1.58$ ), and infant male gender $(\mathrm{OR}=1 \cdot 40$, CI: $1 \cdot 15,1 \cdot 70$ ), (table 3 , column 4). There were no statistically significant interactions between the risk factors in any of the models. We therefore regarded the effect of each factor to be uniform across strata of the other factors, but we realise that the power of formal test for interactions is low.

Separate addition of any of the three variables for country of birth does not contribute significantly to the first or the second model. The adjusted ORs for these three variables are given in table 3 (columns 4 and 5). All adjusted ORs are closer to unity than the crude ORs. Adjustment for any of the country of birth variables has a negligible effect on the ORs for the other variables in the first and the second model (data not shown).

\section{Discussion}

In this population based birth cohort study of perinatal mortality in Amsterdam between 1975 and 1980, independent associations with mortality were seen for maternal age, parity, infant sex, and parental occupational level, but not country of birth of the parents. In infants with an unemployed father the OR for a perinatal death was 1.72 compared with infants with an employed father in the highest occupational level. When both parents or the only parent were unemployed, the OR was 1.44 compared with that in a family with at least one employed parent in the highest occupational level. To the best of our knowledge this association of perinatal mortality with parental employment status adjusted for parental origin and selected biological risk factors has not been reported before. Occupational level per se has much less influence on risk status: the OR for the lowest paternal occupational level compared with the higher occupational levels is 1.33 .

The association between parental country of birth and perinatal mortality is not statistically significant because of the limited number of cases in the population. However, most of the adjusted ORs are also very close to unity. This indicates that the country of birth per se would probably not have been of clinical significance even if more cases had been collected by extending the study period. Since nearly all subjects of non-Dutch origin are first generation immigrants to The Netherlands, no distinction can be made between immigration and ethnicity per se. Such studies may be feasible for the second generation.

From the risk factor distribution among the controls, our best approximation of the situation among the Amsterdam population at large, it can be seen that adverse risk factors for perinatal deaths were more common among families of non-Dutch origin. This mainly explains why the observed association between perinatal mortality and country of origin is more pronounced in univariate than in multivariate analyses. Our findings on the risks associated with maternal age, parity, and paternal occupation are in general agreement with the published reports. ${ }^{3}$

The much reduced association of perinatal mortality with maternal country of birth in this study compared with the earlier analysis of the civil registration data by Doornbos and Nordbeck $^{1}$ can be explained by our exclusion of all multiple births (less than 3\% of infants), our matching of each case with two controls, and our correction of a coding error which mistakenly assigned level 22 occupation to the category "unemployed". We think that our strategy for control selection is more valid than that in the previously reported study and that our findings represent the state of affairs in the population at large. Whereas convenience was the main reason for matching in our study, as the data were collected from registry records which are ordered by date of notification, this procedure effectively adjusts for changes in perinatal mortality differentials that may have occurred over time. As it turns out such changes are not likely because unmatched analyses (not reported here) give essentially the same results. Our findings indicate that for a proper assessment of the role of various factors associated with perinatal mortality and ethnic origin a multivariable analysis including parental employment is essential.

No attempt could be made to look at the effect of biological differences between ethnic groups in birth weight and gestation as these data are not collected by the civil registration authorities. For the same reason birth weight specific mortality rates between ethnic groups could not be explored.

For practical and theoretical reasons infant's ethnicity in this study was defined by the country of birth of its father and mother. The practical reason being that country of birth of both parents is routinely collected at birth registration whereas race or country of birth of grandparents is not. Theoretically, the country of birth may have its limitations but since it is the only objective criterion available in many data sets and nearly all adults of Surinam, Turkish, or Moroccan ethnicity in Holland are first generation immigrants, its use has been specifically recommended for studies of ethnic minorities in The Netherlands. ${ }^{4}$ We cannot exclude the possibility, however, that a small number of Dutch-born parents may in fact have been of non-Dutch ethnic origin (and vice versa). 
The case-control analysis used is the method of choice for the analysis of perinatal mortality because it is the most efficient design to study rare outcomes. ${ }^{5}$ Since this study comprises all reported deaths and, for practical purposes, a random sample of all survivors in a well defined area irrespective of place of delivery, residential area, or date of registration, risk ratios reflecting true incidence ratios could also be derived from the data.

In Amsterdam (1981-82) under reporting of perinatal deaths among infants weighing $1000 \mathrm{~g}$ or over at birth or those with a gestational age of 28 weeks or more was more common among parents of Mediterranean origin (including Turkey and Morocco) than among parents born in The Netherlands $(15 \% v 6 \%)^{6}$ but this is of little practical importance for this study: adjustment for under reporting among parents of Mediterranean origin results in only a small increase in the risk estimates if reporting of mortality is assumed to be unrelated to employment status.

Ethnicity is closely associated with paternal employment and single motherhood in Amsterdam, both in the study period and at present. Among controls born in The Netherlands, $8 \%$ had unemployed husbands and $11 \%$ were unmarried. Among controls of Moroccan and Turkish origin, these figures were $21 \%$ and $9 \%$ respectively, and among controls born in Surinam or The Netherlands Antilles the percentages were $10 \%$ and $55 \%$. This largely explains why there is an univariate association between mortality and parental origin. Differential access to health care between employed and unemployed is not likely to be an explanation for differences in perinatal mortality because almost $100 \%$ of the Dutch population has health insurance, regardless of employment status. Utilization of services may be related to employment status but relevant information hereon is not available.

The decreased perinatal mortality risk among unemployed mothers compared with employed mothers is difficult to interpret given the lack of distinction between voluntary and involuntary unemployment and the lack of data on women's education and motivation, and (by implication) their chances of finding employment. Among unemployed mothers, however, perinatal mortality is lower among married women with employed husbands than among women who are either unmarried or married to an unemployed husband (OR 0.62, data not shown). This suggests that the findings may be biased by the voluntary unemployment of married women at low risk of adverse outcomes.

The increased risk of perinatal mortality in infants with unemployed fathers can be explained in a number of ways. Firstly, unemployment is associated with an increased risk because of the lack of both financial means and a societal network associated with unemployment. Since the social security benefits for the unemployed in The Netherlands in the mid and late 1970 s were probably still at a much higher level than in most other countries, however, this explanation is unlikely but it cannot be ruled out completely.
A second explanation for the increased risk of perinatal mortality associated with unemployment is a common cause of the two phenomena: those with fewer social skills, resources, and education are more likely to be unemployed and more likely to have poor health outcomes. This may apply to immigrants originating from Turkey, Morocco, and Surinam who in part may already have been at a disadvantage in their society of origin, but it may also apply to many from Dutch origin. In the latter explanation the association between unemployment and perinatal mortality is not causal but confounded by unmeasured biological, socioeconomic, and cultural factors which are associated both with unemployment and with perinatal mortality. Adjustment for the perinatal mortality risk factors available did not materially change the relation between unemployment and mortality, which renders the second explanation less likely.

Unmeasured confounding factors may still be operating, however. It is known, for instance, that Surinam born mothers who delivered in Amsterdam in the study period comprised at least two distinct racial/ethnic groups with different health outcomes, namely women of West African and of Asian origin. ${ }^{7}$ The differences in birth weight and gestational age among women of African and Asian origin in Amsterdam agree with comparable studies from California, ${ }^{89}$ and may partly reflect differences in social skills, education, and resources. In the present study the lack of information on parental racial and ethnic origin makes it impossible to distinguish between the two groups born in Surinam.

A third explanation for the increased risk of perinatal mortality may be an excess of biological or behavioural risk factors, or both, among the unemployed which were not measured in this study. The association of perinatal mortality with unemployment is of similar magnitude in all ethnic groups but the risk factors may differ between the groups. We have no information on relevant behavioural risk factors in relation to ethnicity. Whereas it is well known that perinatal mortality is closely related to an infant's gestational age and birth weight, both of which vary by maternal ethnic origin ${ }^{10}$ and possibly indirectly by employment status, these relations could not be explored in the present series as birth certificates in The Netherlands do not include information on either gestational age or birth weight.

Relevant behavioural factors associated with unemployment may include cigarette smoking, ${ }^{11}$ which will affect perinatal mortality by lowering birth weights. In the 1970 British birth cohort, behavioural factors such as knowing the date of one's last menstrual period, reporting early in pregnancy for prenatal visits, participating in childbirth preparation classes, and smoking during pregnancy were related to paternal unemployment. ${ }^{12}$ In England and Wales maternal health behaviour was not a consequence of paternal unemployment, however, as maternal behaviours were similar in women whose husbands were unemployed when their wives delivered, compared with 
women whose husbands had a job at the time of delivery, but who turned out to be unemployed five years later. In the Amsterdam data no such information on behavioural factors is available.

Whereas in all explanations immigrants may form a group with an increased proportion of subjects at higher risk of adverse health outcomes, the public health consequences of the aetiologic models differ. In the first model an improvement in the labour market would bring about better health. In the second model the relative social deprivation of individuals needs to be tackled to improve both their employment and their health status. In the third model selected risky health behaviours of unemployed need to be addressed.

In conclusion, so far studies in multi-ethnic populations have focused on the role of ethnic origin per se. The results of this study suggest that parental employment may be as important, both in immigrants and people born in The Netherlands, and that research with a primary focus on the individual determinants of employment may provide a key towards improved perinatal care. The results of these studies may be especially relevant to immigrant populations, since these groups are at present the most disadvantaged.
We thank J P R Doornbos and $\mathrm{H} J$ Nordbeck for giving us details of their analysis of the registry data and P E Treffers, $H$ Rengelink, and Sarah Santana for their valuable comments.

1 Doornbos JPR, Nordbeck HJ. Perinatal mortality. Obstetric risk factors in a community of mixed ethnic origin in Amrisk factors in a community of mixed ethnic origin
sterdam. Thesis. University of Amsterdam, 1985.

2 EGterdam. Thesis. University of Amsterdam, 1985. demiology and Research Corporation, 1991 .

3 Thomson AM, Barron SL. Perinatal mortality. In: Barron SL, Thomson AM eds. Obstetrical epidemiology. New York: Academic Press, 1983; 347-98.

4 Roelandt Th, Veenman J. Minorities in The Netherlands: Improved measurement 3. (Original in Dutch: Minderheden in Nederland: Beter meten 3; identificatie en classificatie van allochtone personen in registraties en onderzoeken) Rotterdam: ISEO, Erasmus University, 1991.

5 Clarke M, Clayton D. Design and interpretation of casecontrol studies of perinatal mortality. Am $\mathcal{F}$ Epidem 1981; 113:636-45.

6 Doornbos JPR, Nordbeck HJ, Treffers PE. The reliability of perinatal mortality registrations in Amsterdam. (Original in Dutch: De betrouwbarrheid van de registratie van de perinatale sterfte in Nederland, onderzocht voor de gemeente Amsterdam) Ned Tijdschr Geneeskd 1987;131: 913-17.

7 Doornbos JPR, Nordbeck HJ, van Enk AE, Muller AS, Treffers PE. Differential birthweights and the clinical relevance of birthweight standards in a multiethnic society. Int f Gynecol Obstet 1991;34:319-24.

8 Shiono PH, Klebanoff MA, Graubard BI, Berendes HW, Rhoads GG. Birth weight among women of different ethnic groups. $₹ A M A$ 1986;255:48-52.

9 Shiono PH, Klebanoff MA. Ethnic differences in preterm and very preterm delivery. Am $\mathcal{F}$ Public Health 1986;76: and very

10 Barron SL. Birthweight and ethnicity. Br f Obstet Gynaecol 1983;90:289-90.

11 Najman JM, Morrison J, Williams GM, Keeping JD, Andersen MJ. Unemployment and reproductive outcome, an Australian study. Br F Obstet Gynaecol 1989;96:308-13. 12 Golding J, Thomas P, Peters P. Does father's unemployment put the fetus at risk? Br $\mathcal{F}$ Obst Gynaec 1986;93:704-10. 
late 1970 s and is now rising. After allowing for the proportion of births to mothers over 35 years, the trend with year remains significan at the $5 \%$ level, OR $=0.9996, \quad(95 \% \mathrm{CI}$ $0.9995,0.9997)$. Over the period there has also been a steady increase in the proportion of single mothers. As single mothers are more likely to have boys, ${ }^{4}$ it is likely that the decline in the sex ratio of children born to other women is even greater.

This decline in the sex ratio remains unexplained. Possibilities are a general fall in the frequency of intercourse, perhaps due to the increasing stress of society or changes in male or female hormone levels. The latter could be consequence of air pollution which was shown by Williams et al to be associated with a lower sex ratio.

$$
\begin{array}{r}
\text { H O DICKINSON } \\
\text { L PARKER } \\
\text { University of Newcastle } \\
\text { Sir Fames Spence Institute of Child Health } \\
\text { Royal Victoria Infirmary } \\
\text { Newcastle upon Tyne }
\end{array}
$$

This research was supported by grants from the United Kingdom Coordinating Committee on Cancer Research, the North of England Children's Cancer Research Fund and Westlakes Research

1 Harrison PTC, Humphrey CDN, Litchfield M, Peakall D, Schuker LK. Environmental oestrogens: consequences to human health and wildlife. Leicester: MRC Institute for Environment and Health, University of Leicester, 1995.

2 James WH. The human sex ratio. Part 2. A hypothesis and a program of research. Hum Biol 1987;59:873-900.

3 James WH, Rostron J. Parental age, parity and sex ratio in births in England and Wales 1968 sex ratio in births in England and Wales 196856.

4 James WH. The human sex ratio. Part 1: A review of the literature. Hum Biol 1987;59:721-52.

5 Williams FL, Lawson AB, Lloyd OL. Low sex ratios of births in areas at risk from air pollution from incinerators, as shown by geographical analysis and 3-dimensional mapping. Int $\mathcal{F} E \mathrm{p} i$ demiol 1992;21:311-19.

\section{Comparing measures of variation}

Sir - We recently reported levels of geographical variation in hospital admission rates in the Oxford region. ${ }^{1}$ In discussing our results, we briefly compared systematic component of variation (SCV) values from our data with those published by Wennberg et al for hospital service areas in Maine, USA Wennberg et al described their method by citing an earlier paper in which SCVs had been calculated using a multiplication constant of $100 .^{3}$ We now believe that in the 1984 study $^{2}$ they in fact used a multiplication factor of 1000 , although it is impossible to discover this from their paper.

The reported differences between our results and those from Maine persist, however after taking account of the 10-fold multiplication factor. Only $10 \%$ of admissions in Maine were for conditions with an SCV (100) of less than $5 \cdot 0$, compared with $44 \%$ of surgical workload in Oxford.

Our conclusion remains unchanged. There was substantially less variation in admission rates in the Oxford region than in Maine, USA.

JOHN NEWTON VALERIE SEAGROATT MICHAEL GOLDACRE Unit of Health-Care Epidemiology, Department of Public Health, and Primary Care,
University of Oxford.

1 Newton JN, Seagroatt V, Goldacre M. Geographical variation in hospital admission rates: an analysis of workload in the Oxford region England. 7 Epidemiol Community Health 1994; 48:590-95.

2 Wennberg JE, McPherson K, Caper P. Will payment based on diagnosis-related groups control hospital costs? N Engl f Med 1984;311: 295-300.

3 McPherson K, Wennberg JE, Horind OB, Clifford P. Small-area variations in the use of com-
mon surgical procedures: an international mon surgical procedures: an international
comparison of New England, England, and Norway. $N$ Engl f Med 1982;307:1310-14.

\section{Perinatal mortality in a first generation immigrant population and its relation to unemployment in The Netherlands}

Sir - In the introduction of the above article we stated in error that a previous study by Doornbos and Nordbeck of the same population ${ }^{2}$ showed an odds ratio of $\mathbf{1 . 5 0}$ for perinatal mortality for infants of Surinam origin and of 1.42 for infants of other non-Dutch origin. In fact, these authors reported crude odds ratios of 1.23 and 1.22 for the two groups. The error resulted from a misreading of data provided by these authors.

Our re-analysis of the role of various factors associated with perinatal mortality and ethnic origin therefore confirms the simpler Doornbos/Nordbeck analysis with respect to the marginal role of infant origin itself.

The main finding of our report regarding the important role of parental employment status as a predictor of perinatal mortality is not affected.

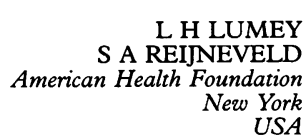

1 Lumey LH, Reijneveld SA. Perinatal mortality in a first generation immigrant population and its relation to unemployment in The Netherlands. F Epidemiol Community Health 1995; 49:434-9.

2 Doornbos JPR, Nordbeck HJ. Perinatal mortality. Obstetric risk factors in a community of mixed ethnic origin in Amsterdam (proefschrift). Amsterdam: Universiteit of Amsterdam, 1985.

\section{NOTICES}

\section{European Journal of Public Health $(1996 ; 6)$}

The contents of the European Fournal of Public Health for June 1996 are as follows.

Looking back and ahead: a bright view for the journal (ed) Palm J, Svensson P-G.

ORIGINAL ARTICLES:

Sharing syringes in Madrid: a social phenomenon Rodrigues-Arenas MA, Zunzunegui Pastor MV, Friedman SR, et al.

Prevalence and trends of cigarette smoking in different occupational groups: results of the Minnesota heart survey 1980-1982 and 1985-1987 Knutsson A, Luepker RV, Sprafka JM, Virnig B.

The effectiveness of treatment for the prolapsed lumbar intervertebral disc: a review of the lit erature Deane $\mathrm{M}$, Moore AJ, Long AF, Harrison $\mathrm{S}$

Working in the field: the psychiatric nurse as a libero in the community health services Hummelvoll JK.

Proposals for collaboration in European public health training Köhler L, Bury JA, de Leeuw E, Vaughan $\mathrm{P}$

Health expectancy in the Netherlands 19831990 van de Water HPA, Boshuizen HC, Perenboom RJM.

Functional ability scales for the elderly. $A$ validation study Avlund K, Kreiner S, SchultzLarsen $\mathrm{K}$.

Detection of depressive complaints in children Kroesbergen HT, de Wit C, Stijnen T.

The French breast cancer screening programme: epidemiological and economic results of the first round of screening Wait $\mathrm{SH}$, Allemand HM

A study of general practitioners' prescribing behaviour to the elderly in Wallonia, Belgium Taziaux P, Franck J, Ludovicy R, Albert A.

The incidence of hypertension and the effects of a regular high-dose alcohol intake on blood pressure in a medium-sized Hungarian town (Csonhrád) Mohácsi G, Abrahám G, Remes P, Lovas S, Sonkodi S.

Uncertainty and lack of trust with Parkinson's disease Nijhof $\mathrm{G}$.

Book reviews, Calendar of Events, EIPHA pages 